graphy for the clinical pictures, to Professor T. F. Hewer for facilities for microphotography, and to Dr. A. L. Taylor for the sections. Supplies of testosterone isobutyrate were kindly made by Messrs. Ciba, and testosterone phenylpropionate by Organon Laboratories.

\section{REFERENCES}

Anderson, C. M., Frazer, A. C., French, J. M., Gerrard, J. W., Sammons, H. C., and Smellie, J. M. (1952). Lancet, 1 836.

Bayley, N, and Pinneau, S. R. (1952). J. Pediat., 40, 423.
Dicke, W. K., Weijers, H. A., and Kamer, J. H. van de (1953). Acta paediat. (Uppsula), 42, 34. and Smellie, J. M. (1955). Lancet, 1, 587. Astley. R. Prench, J. M., and Smellie, J. M. (1955) Quart. J. Med.. 24, 23.

Greulich W. W. and Pyle, S. I. (1959). Radiographic Atlas of Skeletal Development of the Hand and Wrist. 2nd ed. Stanford Univ. Press, Stanford. Oxford Univ. Press, London.

Hardwick, C. (1939). Arch. Dis. Childh., 14, 279.

Lindsay, M. K. M., Nordin, B. E. C., and Norman, A. P. (1956). Brit. med. J.. 1, 14. and Lawson, D. (1952). Ibid., 2, 902.

Sheldon, W. (1955). Lancet, 2, 1097.

\title{
CONTROLLED TRIAL OF HYPNOSIS IN THE SYMPTOMATIC TREATMENT OF ASTHMA
}

\section{G. P. MAHER-LOUGHNAN, M.A., D.M. Consultant Physician, Colindale and Whittington Hospitats, London}

A. A. MASON, M.B., B.S. Clinical Assistant, Psychiatric Department, King's College Hospital, London

Hypnotism has been used as a method of treatment for various psychoneuroses and in psychosomatic disorders for hundreds if not thousands of years. Varying reports about its efficacy in the treatment of asthma have recently appeared in the literature. Magonet (1955), Fry (1957), Ambrose and Newbold (1958), and Meares (1960) have all claimed good symptomatic relief for even the most severe cases of asthma, and Stewart (1957) reported nine complete remissions out of 12 cases of asthma, with partial remissions in two. It is clear that what has been described by these previous publications has been based on clinical impressions and there had been no properly controlled studies. Furthermore, the authors employed various degrees of psychotherapy with their hypnotic suggestions, most insisting that psychotherapy was an essential part of the treatment.

Morrison Smith and Burns (1960), in the only controlled study yet published, found that hypnotic suggestion failed to give any improvement, either immediate or delayed, in a series of 25 children. However, their treatment extended over a period of a month only.

This paper sets out to assess, in a controlled study over a longer period, the value of suggestion in the hypnotic state against suggestion produced by any new method of symptomatic treatment.

\section{Method}

Two groups of asthmatic subjects, allocated by random selection, were treated as out-patients for six months, after one month's observation; one group was treated by hypnosis, and another, to serve as a control, was given a bronchodilator new to the patients. Intake to the trial lasted for 12 months-from October, 1959, to September, 1960.

Patients Accepted.-Patients were new to the asthma clinics, and were invited to take part in the trial on arrival. Subjects of any age and either sex were eligible ; all declared themselves willing to undergo hypnosis or to accept a new drug ; asthma had to be present for at least one year. Patients were excluded who had repeated attacks of bronchitis or who produced regularly more than $2 \mathrm{oz}$. $(60 \mathrm{ml}$.) of sputum daily; so were subjects

\author{
N. MACDONALD, M.D., F.R.C.P.Ed. \\ Consultant Physician, Clare Hall Hospital and \\ Hitchin Chest Clinic \\ LIONEL FRY, M.B., B.Sc., M.R.C.P. \\ Medical Registrar, King's College Hospital, \\ London
}

with emphysema or pulmonary fibrosis as seen on an $x$-ray film, subjects with bronchiectasis demonstrated by bronchography, and those with a history of earlier psychotic breakdown. No patient who was on continuous treatment would be acceptable to the trial and in fact no steroids were employed during it.

Assessments at Start of Observation Month.-When a patient had been accepted notes were made on whether the asthma was triggered off by known antigens, infections, or physical or emotional factors. Degrees of severity of asthma were recorded as: mild, those whose main symptom was a non-continuous wheeze and who had experienced fewer than two severe attacks a year; medium-cases with 2 to 12 severe attacks a year; or severe - cases with uninterrupted spasm or more than 12 severe attacks a year. An attack was defined as spasm severe enough to prevent work, school attendance, or other normal activities. Notes were also made on the length of asthmatic history, and season in which attacks were worse. Patients were examined and $x$-rayed, and eosinophils were sought in blood and sputum. They were then issued with a diary and instructed in a simple coding technique similar to that employed successfully in chronic bronchitis trials (Waller et al., 1957 ; Francis and Spicer, 1960). They were instructed to write two letters each day. One related to wheeziness: $A=$ absence of wheeze (arbitrarily assigned a score of 0 ), $B=$ occasional wheezes (score 1 ), $\mathrm{C}=$ wheezing for two hours or more (score 2), $\mathrm{D}=$ attack of asthma (score 3). The second letter related to drug (tablet or inhaler) employed as a relief when spasm occurred-recorded as T (tablet) or P (pump), with the number of times used each day. The patients were told to make these diary entries daily while living what for them was a normal life. Each patient was seen briefly half-way through the observation month, only to ascertain that diary recordings were being entered accurately and without difficulty.

After the observation month all continued to take emergency bronchodilators, controls now employing the newly issued ones and patients in the hypnosis group using what they had previously used; and daily diaryrecording continued. 


\section{Treatment}

During the first "observation" month no new treatment was introduced, so that the recordings might serve as a yardstick against which future changes could be measured. After this month each patient reported back and was allocated at random to one of the two groups.

Three centres were involved in the study; unavoidably, there were differences in handling procedure between one centre and the other two. In one (later called centre C) patients were seen for assessment throughout the trial by the chest physician, but the hypnosis patients were referred to the psychiatric department, where diary recordings were also noted and treatment was given. In the other two centres (A and B) one chest physician dealt with both groups of patients throughout.

\section{Hypnosis Group}

Patients were given a first hypnotic induction, each physician using the technique to which he was accustomed. The techniques in centres $A$ and $B$ were essentially similar-eye-fixation coupled with handelevation and eye-fixation alone, both producing rapid states of trance ; centre $\mathrm{C}$ employed progressive relaxation, which, being a more gradual technique, takes longer to produce a trance.

After induction a note was made of the method and of the time taken; the trance was then deepened maximally and the depth of trance was recorded. Three levels were defined: light, as when the eyelids closed in cataleptic fashion after normal induction but the patient responded to no further "test" suggestions ; medium, the patient responding to suggestion of hand levitation and/or partial anaesthesia; and deep, the patient experiencing complete anaesthesia and/or induced amnesia. Once the patient became used to hypnosis, training in relaxation under autohypnosis was instituted whenever possible. Each patient was told to repeat a signal which, by preconditioning, had produced a hypnotic trance lasting for precisely half an hour. Each day for this specified period the patient would remain in a state of relaxation, but would not repeat any therapeutic suggestions.

The patient was seen thereafter, the routine assessments being made; they were again hypnotized and given symptom-removal suggestions at intervals of 1,2 , $4,6,8,12,16,20$, and 24 weeks, to complete the study. No attempt was made to use hypno-analysis or other psychological adjustment.

\section{Control Group}

It was realized that controls would require careful handling, so they were given symptomatic remedies (listed in Table III) which they had not used before. Care was taken at the beginning to explain to all the patients, in an attempt to avoid bias, that hypnosis or the new drug might be of greater value in treatmentthat one or the other would be given for six months, and, if ineffective, the other might be employed. A new remedy was issued to the controls, and they were seen thereafter at the same intervals and for the same length of time as the hypnosis patients. When the six-months period of treatment was over, physicians were free to give or to continue hypnosis to patients from either group.

\section{Findings in the Observation Month}

Sixty-two patients volunteered for the trial. Five did not complete the trial-three were allocated to the hypnotherapy group (two failed to attend after only one session of hypnosis and one could not be hypnotized), one was allocated to the control group and left the trial after the third month, and the fifth died in status asthmaticus during the observation month and before she had been allocated to a group. Two more were excluded from analysis: one was in the hypnosis group because he was found to have left lower-lobe bronchiectasis after a haemoptysis in the fifth month of treatment; the other, who had been allocated to the control group, was found in the first month to be producing 3-4 oz. (85-114 ml.) of sputum daily

Fifty-five patients (27 in the hypnosis group and 28 in the control group) remained for analysis. Table I shows the condition of the patients at the start of the

TABle I.-Observations on Admission

\begin{tabular}{|c|c|c|c|c|c|}
\hline & & & & Hypnosis Group & Control Group \\
\hline $\begin{array}{c}\text { Total No. o } \\
\text { Centre }\end{array}$ & 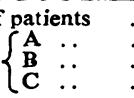 & $\begin{array}{l}\cdots \\
\cdots \\
\cdots\end{array}$ & $\begin{array}{l}\ldots \\
\cdots \\
\ldots\end{array}$ & $\begin{array}{r}27 \\
14 \\
6 \\
7\end{array}$ & $\begin{array}{r}28 \\
11 \\
7 \\
10\end{array}$ \\
\hline Sex & $\left\{\begin{array}{l}\text { Male } \\
\text { Female }\end{array}\right.$ & . & $\therefore$ & $\begin{array}{l}14 \\
13\end{array}$ & $\begin{array}{r}8 \\
20\end{array}$ \\
\hline $\begin{array}{c}\text { Age } \\
\text { (years) }\end{array}$ & $\left\{\begin{array}{c}6-9 \\
10-19 \\
20-29 \\
30-39 \\
40-59\end{array}\right.$ & $\begin{array}{l}\ldots \\
\cdots \\
\cdots\end{array}$ & $\begin{array}{l}\ldots \\
\cdots \\
\cdots \\
\cdots\end{array}$ & $\begin{array}{r}2 \\
7 \\
10 \\
6 \\
2\end{array}$ & $\begin{array}{r}2 \\
10 \\
8 \\
4 \\
4\end{array}$ \\
\hline $\begin{array}{c}\text { Physical } \\
\text { type }\end{array}$ & $\left\{\begin{array}{l}\text { Thin } \\
\text { Muscular } \\
\text { Fat }\end{array}\right.$ & $\begin{array}{l}. \\
\cdots\end{array}$ & $\begin{array}{l}\cdots \\
\cdots\end{array}$ & $\begin{array}{r}4 \\
19 \\
4\end{array}$ & $\begin{array}{r}8 \\
13 \\
7\end{array}$ \\
\hline $\begin{array}{l}\text { Degree } \\
\text { of } \\
\text { asthma }\end{array}$ & $\left\{\begin{array}{l}\text { Mild } \\
\text { Medium } \\
\text { Severe }\end{array}\right.$ & 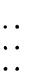 & $\begin{array}{l}\cdots \\
\cdots\end{array}$ & $\begin{array}{r}4 \\
13 \\
10\end{array}$ & $\begin{array}{r}7 \\
16 \\
5\end{array}$ \\
\hline $\begin{array}{l}\text { No. } \\
\text { of } \\
\text { triggers }\end{array}$ & $\begin{cases}\text { None } \\
1 & \cdots \\
2 & \cdots \\
3 & \cdots \\
4 & \cdots\end{cases}$ & $\begin{array}{l}. \\
\therefore \\
\cdots\end{array}$ & $\begin{array}{l}\ldots \\
\cdots \\
\cdots \\
\cdots\end{array}$ & $\begin{array}{r}3 \\
5 \\
5 \\
10 \\
4\end{array}$ & $\begin{array}{r}2 \\
7 \\
12 \\
6 \\
1\end{array}$ \\
\hline $\begin{array}{l}\text { Type of } \\
\text { triggers }\end{array}$ & $\left\{\begin{array}{l}\text { Antigens } \\
\text { Infections } \\
\text { Physical } \\
\text { Emotional }\end{array}\right.$ & $\begin{array}{l}\cdots \\
\cdots\end{array}$ & $\begin{array}{l}\ldots \\
\cdots \\
\cdots\end{array}$ & $\begin{array}{l}16 \\
12 \\
16 \\
17\end{array}$ & $\begin{array}{l}10 \\
15 \\
13 \\
15\end{array}$ \\
\hline $\begin{array}{l}\text { No. of } \\
\text { seasonal } \\
\text { peaks }\end{array}$ & $\begin{array}{ll}1 & \cdots \\
2 & \cdots \\
3 & \cdots \\
4 & \cdots\end{array}$ & $\begin{array}{l}\cdots \\
\cdots \\
\cdots\end{array}$ & $\begin{array}{l}\cdots \\
\cdots \\
\cdots\end{array}$ & $\begin{array}{r}9 \\
10 \\
1 \\
7\end{array}$ & $\begin{array}{r}5 \\
9 \\
2 \\
12\end{array}$ \\
\hline $\begin{array}{c}\text { Season } \\
\text { peak }\end{array}$ & $\begin{array}{l}\text { Spring } \\
\text { Summer : } \\
\text { Autumn : } \\
\text { Winter : }\end{array}$ & $\begin{array}{l}\ldots \\
\cdots \\
\cdots\end{array}$ & $\begin{array}{l}\ldots \\
\cdots \\
\ldots\end{array}$ & $\begin{array}{l}12 \\
18 \\
17 \\
13\end{array}$ & $\begin{array}{l}16 \\
24 \\
20 \\
17\end{array}$ \\
\hline $\begin{array}{l}\text { Length of } \\
\text { history } \\
\text { (years) }\end{array}$ & $\left\{\begin{array}{l}1-9 \\
10-19 \\
20 \text { or more }\end{array}\right.$ & . & $\begin{array}{l}\cdots \\
\cdots \\
\cdots\end{array}$ & $\begin{array}{r}9 \\
12 \\
6\end{array}$ & $\begin{array}{r}15 \\
9 \\
4\end{array}$ \\
\hline $\begin{array}{l}\text { No. of } \\
\text { allied } \\
\text { illnesses }\end{array}$ & $\left\{\begin{array}{l}\text { None } \\
1 \quad \cdots \\
2 \quad \cdots \\
3 \text { or } \text { more }\end{array}\right.$ & $\begin{array}{l}\cdots \\
\cdots\end{array}$ & $\begin{array}{l}\ldots \\
\cdots \\
\cdots\end{array}$ & $\begin{array}{l}8 \\
7 \\
9 \\
3\end{array}$ & $\begin{array}{r}12 \\
4 \\
12 \\
0\end{array}$ \\
\hline
\end{tabular}

trial. There were some differences. The controls included more women and fewer of the musoular type of persons, and half as many with severe asthma. There were also fewer patients whose asthma had three or four triggers, fewer whose asthma was associated with known antigens, but more had shorter histories and more had asthma all the year round.

Table II gives details of the hypnotherapy. There were considerable differences between the centres; the two which employed hand and/or eye fixation took two to four minutes for the first induction; the one using progressive relaxation took an average of 11 minutes. In centre $A$ almost all the patients were easy to hypnotize, the majority deeply so (no deep hypnosis was obtained by the other two centres) and all achieved autohypnosis. 
Table III gives details of treatment of the controls. The "medihaler" proved the primary new treatment; breathing exercises were also introduced in centre $C$ to six patients.

\begin{tabular}{|c|c|c|c|c|c|c|}
\hline & & & \multicolumn{3}{|c|}{ Method of Hypnosis } & \multirow{2}{*}{$\begin{array}{c}\text { Total } \\
\text { in } \\
\text { Hypnosis } \\
\text { Group }\end{array}$} \\
\hline & & & $\begin{array}{c}\text { Hand/Eye } \\
\text { Fixation }\end{array}$ & $\begin{array}{l}\text { Eye } \\
\text { Fixation }\end{array}$ & $\begin{array}{l}\text { Progressive } \\
\text { Relaxation }\end{array}$ & \\
\hline Centre & . & . & $\mathbf{A}$ & B & $\mathbf{C}$ & \\
\hline \multicolumn{3}{|c|}{$\begin{array}{l}\text { Total No. of patients } \\
\text { Average time for first induc- }\end{array}$} & & & 7 & 27 \\
\hline $\begin{array}{c}\text { tion (mi } \\
\text { Ease } \\
\text { of } \\
\text { hypnosis }\end{array}$ & $\begin{array}{l}\text { S.) Easy } \\
\text { Medium } \\
\text { Difficult }\end{array}$ & $\begin{array}{l}\cdots \\
\cdots \\
\cdots\end{array}$ & $\begin{array}{c}3 \cdot 8 \\
11 \\
2 \\
1\end{array}$ & $\begin{array}{l}2 \cdot 4 \\
3 \\
2 \\
1\end{array}$ & $\begin{array}{c}11 \cdot 0 \\
3 \\
3 \\
1\end{array}$ & $\begin{array}{r}77 \\
7 \\
3\end{array}$ \\
\hline $\begin{array}{c}\text { Depth } \\
\text { of } \\
\text { hypnosis }\end{array}$ & $\begin{array}{l}\text { Light } \\
\text { Medium } \\
\text { Deep }\end{array}$ & $\begin{array}{l}. \\
.\end{array}$ & $\begin{array}{r}1 \\
3 \\
10\end{array}$ & $\begin{array}{l}2 \\
4 \\
0\end{array}$ & $\begin{array}{l}3 \\
4 \\
0\end{array}$ & $\begin{array}{r}6 \\
11 \\
10\end{array}$ \\
\hline $\begin{array}{c}\text { Auto- } \\
\text { hypnosis }\end{array}$ & $\left\{\begin{array}{l}\text { Yes } \\
\text { No }\end{array}\right.$ & $\because$ & $\begin{array}{r}14 \\
0\end{array}$ & $\begin{array}{l}5 \\
1\end{array}$ & $\begin{array}{l}3 \\
4\end{array}$ & $\begin{array}{r}22 \\
5\end{array}$ \\
\hline
\end{tabular}

TABLE III.-Treatment Received by Control Group

\begin{tabular}{|c|c|c|}
\hline Centre & Treatment & $\begin{array}{l}\text { No. of } \\
\text { Patients }\end{array}$ \\
\hline A (11 patients) & 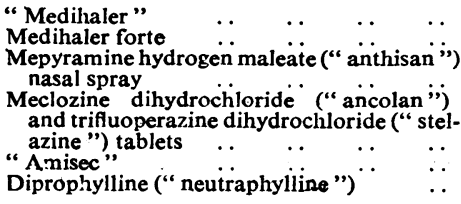 & $\begin{array}{r}11 \\
1 \\
1\end{array}$ \\
\hline B (7 patients) & 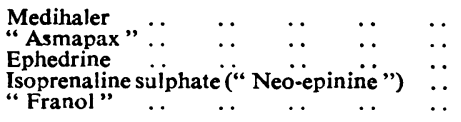 & $\begin{array}{l}7 \\
1 \\
1 \\
1 \\
1\end{array}$ \\
\hline \multirow[t]{2}{*}{ C (10 patients) } & 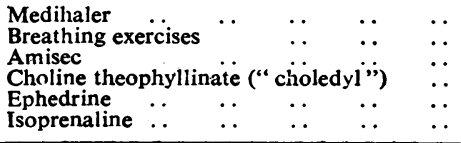 & $\begin{array}{l}6 \\
6 \\
4 \\
6 \\
8 \\
3 \\
3\end{array}$ \\
\hline & 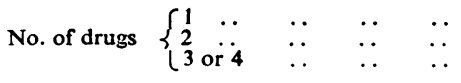 & $\begin{array}{l}2 \\
6 \\
2\end{array}$ \\
\hline
\end{tabular}

\section{Results}

Table IV shows the progress of asthma according to the average number of days per month with wheezing.

TABLE IV.-Condition of Asthma During Treatment, According to Average Number of Days Per Month with Wheezing

\begin{tabular}{|c|c|c|c|c|c|c|c|}
\hline \multirow{3}{*}{\multicolumn{2}{|c|}{$\begin{array}{l}\text { Month of } \\
\text { Treatment }\end{array}$}} & \multicolumn{6}{|c|}{ Average No. of Days per Month* with } \\
\hline & & \multicolumn{2}{|c|}{$\begin{array}{c}\text { No } \\
\text { Wheeze }\end{array}$} & \multicolumn{2}{|c|}{$\begin{array}{l}\text { Occasional } \\
\text { Wheeze }\end{array}$} & \multicolumn{2}{|c|}{$\begin{array}{l}\text { Continuous or } \\
\text { Severe Wheeze }\end{array}$} \\
\hline & & H & C & $\mathbf{H}$ & C & H & C \\
\hline $\begin{array}{cc}\text { Observation } \\
\begin{array}{c}1 \\
2\end{array} \\
3 & \cdots \\
4 & \cdots \\
5 & \cdots \\
6 & \ldots\end{array}$ & $\begin{array}{l}\because \\
\because\end{array}$ & $\begin{array}{l}6 \\
11 \\
16 \\
17 \\
16 \\
18 \\
18\end{array}$ & $\begin{array}{r}19 \\
111 \\
11 \\
12 \\
11 \\
11 \\
10\end{array}$ & $\begin{array}{r}18 \\
14 \\
9 \\
10 \\
10 \\
9 \\
9\end{array}$ & $\begin{array}{l}15 \\
14 \\
15 \\
13 \\
14 \\
14 \\
16\end{array}$ & $\begin{array}{l}4 \\
3 \\
3 \\
1 \\
2 \\
1 \\
1\end{array}$ & $\begin{array}{l}3 \\
3 \\
2 \\
3 \\
3 \\
3 \\
2\end{array}$ \\
\hline
\end{tabular}

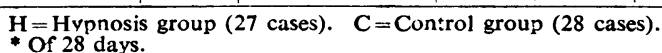

Although the hypnosis group had a greater amount of wheezing during the observation month, the table shows the marked improvement which occurred in the subsequent months of treatment; the average number of days per month with no wheezing increased threefold, from 6 in the observation month to 18 at five and six months, so that more than half of the month was clear of asthma ; this was accentuated by five subjects who by six months had started regularly to experience 28 clear days and by seven who were nearing a complete remission. By contrast, there was very little alteration in the condition of the control group throughout the six months (in fact, four patients in the group experienced alleviation of spasm, but this was offset by others who got worse in the same period).

Table $\mathrm{V}$ shows the asthma pattern according to the number of patients with different "scores" of wheezing each month: it shows the same picture as Table IV but brings out more clearly the shift towards a remission in

TABle V.-Condition of Asthma During Treatment: According to Average "Score" of Wheezing per Month

\begin{tabular}{|c|c|c|c|c|c|c|c|c|c|c|}
\hline \multirow{3}{*}{$\begin{array}{l}\text { Month of } \\
\text { Treatment }\end{array}$} & \multicolumn{10}{|c|}{ No. of Patients with "Score" of Wheezing per Month } \\
\hline & \multicolumn{2}{|c|}{$\mathbf{O}$} & \multicolumn{2}{|c|}{$1-14$} & \multicolumn{2}{|c|}{$15-29$} & \multicolumn{2}{|c|}{$30+$} & \multicolumn{2}{|c|}{$\begin{array}{c}\text { Average } \\
\text { Score }\end{array}$} \\
\hline & H & C & $\mathbf{H}$ & C & $\mathbf{H}$ & C & $\mathbf{H}$ & C & $\mathbf{H}$ & C \\
\hline $\begin{array}{cc}\text { bservation } \\
1 & \\
2 & \\
3 & \\
4 & . \\
5 & . \\
6 & .\end{array}$ & $\begin{array}{l}0 \\
0 \\
2 \\
6 \\
7 \\
5 \\
5\end{array}$ & $\begin{array}{l}0 \\
1 \\
1 \\
4 \\
2 \\
2 \\
2\end{array}$ & $\begin{array}{r}4 \\
8 \\
15 \\
10 \\
6 \\
13 \\
11\end{array}$ & $\begin{array}{l}8 \\
9 \\
9 \\
6 \\
8 \\
8 \\
8\end{array}$ & $\begin{array}{r}12 \\
14 \\
5 \\
9 \\
9 \\
6 \\
9\end{array}$ & $\begin{array}{l}12 \\
11 \\
12 \\
11 \\
11 \\
11 \\
14\end{array}$ & $\begin{array}{r}11 \\
5 \\
5 \\
2 \\
6 \\
3 \\
2\end{array}$ & $\begin{array}{l}8 \\
7 \\
6 \\
7 \\
7\end{array}$ & $\begin{array}{l}27 \\
22 \\
15 \\
13 \\
15 \\
13 \\
13\end{array}$ & $\begin{array}{l}23 \\
22 \\
21 \\
21 \\
23 \\
20 \\
20\end{array}$ \\
\hline
\end{tabular}

H= Hypnosis group (27 cases). $\quad$ C = Control group (28 cases)

the hypnosis group. The average score was reduced by half, from 27 in the observation month to 13 at five or six months. The average scores between three and six months in the hypnosis group differ significantly (at the $5 \%$ level) from those for the observation month. In contrast, as before, the controls showed only very little alteration in the average score.

The Chart illustrates the differences, by average "scores," between the two groups.

Table VI indicates the changes in the use of bronchodilators during the trial, giving a quantitative index of

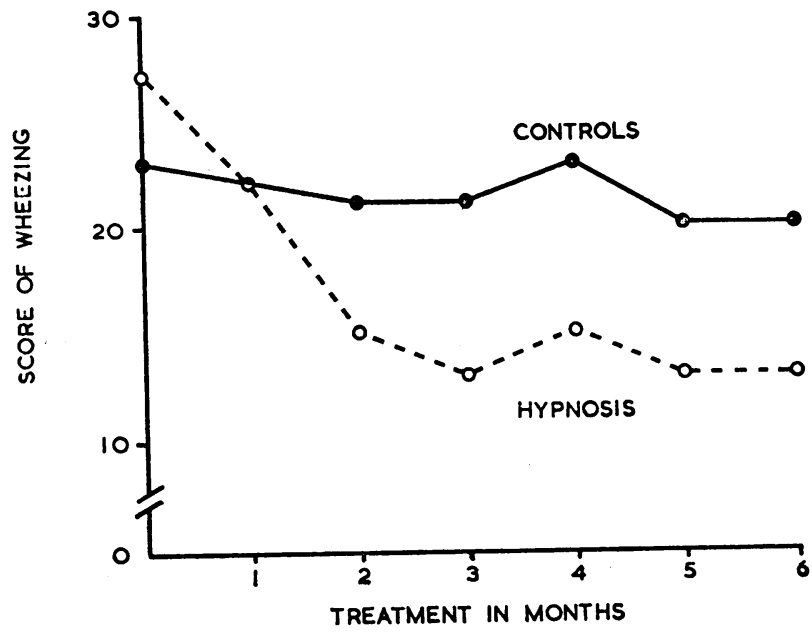

Progress of asthma according to average score of wheezing. TABLE VI.-Use of Bronchodilators

\begin{tabular}{|c|c|c|c|c|c|c|c|c|c|}
\hline \multirow{3}{*}{\multicolumn{2}{|c|}{$\begin{array}{c}\text { Month } \\
\text { of } \\
\text { Treatment }\end{array}$}} & \multicolumn{8}{|c|}{ No. of Times per Month Bronch dilator Used } \\
\hline & & \multicolumn{2}{|c|}{0} & \multicolumn{2}{|c|}{$1-14$} & \multicolumn{2}{|c|}{$15+$} & \multicolumn{2}{|c|}{$\begin{array}{l}\text { Average No } \\
\text { of Times } \\
\text { Pump Used }\end{array}$} \\
\hline & & $\mathbf{H}$ & $\mathbf{C}$ & $\mathbf{H}$ & $\mathbf{C}$ & $\mathbf{H}$ & C & $\mathbf{H}$ & C \\
\hline 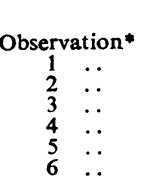 & $\begin{array}{l}. \\
\because \\
\because \\
. \\
. \\
.\end{array}$ & $\begin{array}{l}1 \\
1 \\
4 \\
6 \\
6 \\
6 \\
8 \\
8\end{array}$ & $\begin{array}{l}0 \\
0 \\
0 \\
2 \\
2 \\
1 \\
1\end{array}$ & $\begin{array}{r}\text { No. } \\
5 \\
9 \\
7 \\
5 \\
8 \\
8 \\
6\end{array}$ & $\begin{array}{r}\text { Pat } \\
5 \\
8 \\
6 \\
5 \\
5 \\
4 \\
6\end{array}$ & $\begin{array}{r}\text { ts } \\
14 \\
10 \\
9 \\
9 \\
6 \\
6 \\
6\end{array}$ & $\begin{array}{l}14 \\
13 \\
15 \\
14 \\
14 \\
16 \\
14\end{array}$ & $\begin{array}{l}89 \\
57 \\
59 \\
33 \\
26 \\
29 \\
22\end{array}$ & $\begin{array}{l}60 \\
59 \\
58 \\
64 \\
76 \\
74 \\
70\end{array}$ \\
\hline
\end{tabular}

$\mathrm{H}=$ Hypnosis group (20 patients). $\mathrm{C}=$ Control group (21 patients) * No punp was issued to 2 control patients during the month of observation. 
the times asthmatic sufferers needed help. The hypnosis group used pills or pumps more often during the observation month than the control group, but less during the succeeding months, and the number of times was greatly reduced by the sixth month. By contrast there were only slight changes in the control group.

Table VII gives the symptomatic course of the asthma as indicated by average "scores" of wheezing during treatment according to the data given in Table I. In the hypnosis group there was marked reduction in the average score of wheezing for all categories of the observations on admission. The most important differences were those between the three centres: $A$ and B started with similar amounts of wheezing in the observation and first month and were closely similar at the end of the trial ; centre B dropped more rapidly in between. Centre $\mathrm{C}$ had a higher score of wheezing throughout ; although a reduction in score was produced it was not nearly so great as in the other two centres. Possible reasons for these and other differences are considered in the discussion.

The three physicians giving hypnosis were all male, yet there was no difference in the response between the male and female patients. The patients aged less than 20 and those between 20 and 29 years made similar progress; those aged 30 years or over did less well.

All three degrees of asthma fared well; the few with mild asthma made much greater improvement than those with medium or severe asthma; there was little difference between the two latter. Patients who had asthma for 1-9 and for 10-19 years made better progress than those who had it for 20 years or more ; the latter also had a higher score initially. Most patients had more than one type of trigger; those with an emotional trigger responded best to hypnotherapy, but those with the other three types did almost as well.

The patients found easy to hypnotize achieved the most progress, and the few found difficult achieved the least. Those who were light trance subjects did least well ; those who were medium or deep trance subjects showed similar improvement by five and six months, but, curiously, those of medium depth were much better in the intervening months. The patients in whom autohypnosis was achieved did much better than the few in whom this was not possible.

In the control group there was very little alteration in the score as the trial progressed; however, minor variations occurred, according to the observations on admission. Centre B had the lowest score of wheezing in the observation month, and centre $\mathrm{C}$ the highest ; those aged less than 20 years had the lowest and those aged 30 or more the highest. The patients whose degree of asthma was severe and who had a length of history of 20 years or more also started with a greater amount of wheezing. Those whose asthma was infectious in type had a lower score of wheezing than the others.

\section{Discussion}

Asthma is influenced by three main factors-allergic, infective, and psychological. Each patient may be affected by one or more of these at any time. No specific cure for asthma has been recognized, apart from desensitization in certain allergic subjects; even this often does not have the required result. Most modern treatment would be termed symptomatic, and some of the measures employed, such as steroids, have still to be finally assessed, epecially with regard to side-effects after long-term administration.

The results show great symptomatic improvement in the hypnotherapy group in that the wheezing was reduced on an average by about half within three months, but there was very little alteration in the condition of the controls.

Controlled trials of asthma are hard to plan because of the problem of therapy for the "controls." Here it was decided for the controls to use treatment by an antispasmodic which was new to the patient. As is

Table V.-Condition of Asthma During Treatment, According to Observations on Admission and Details of the Hypnotherapy

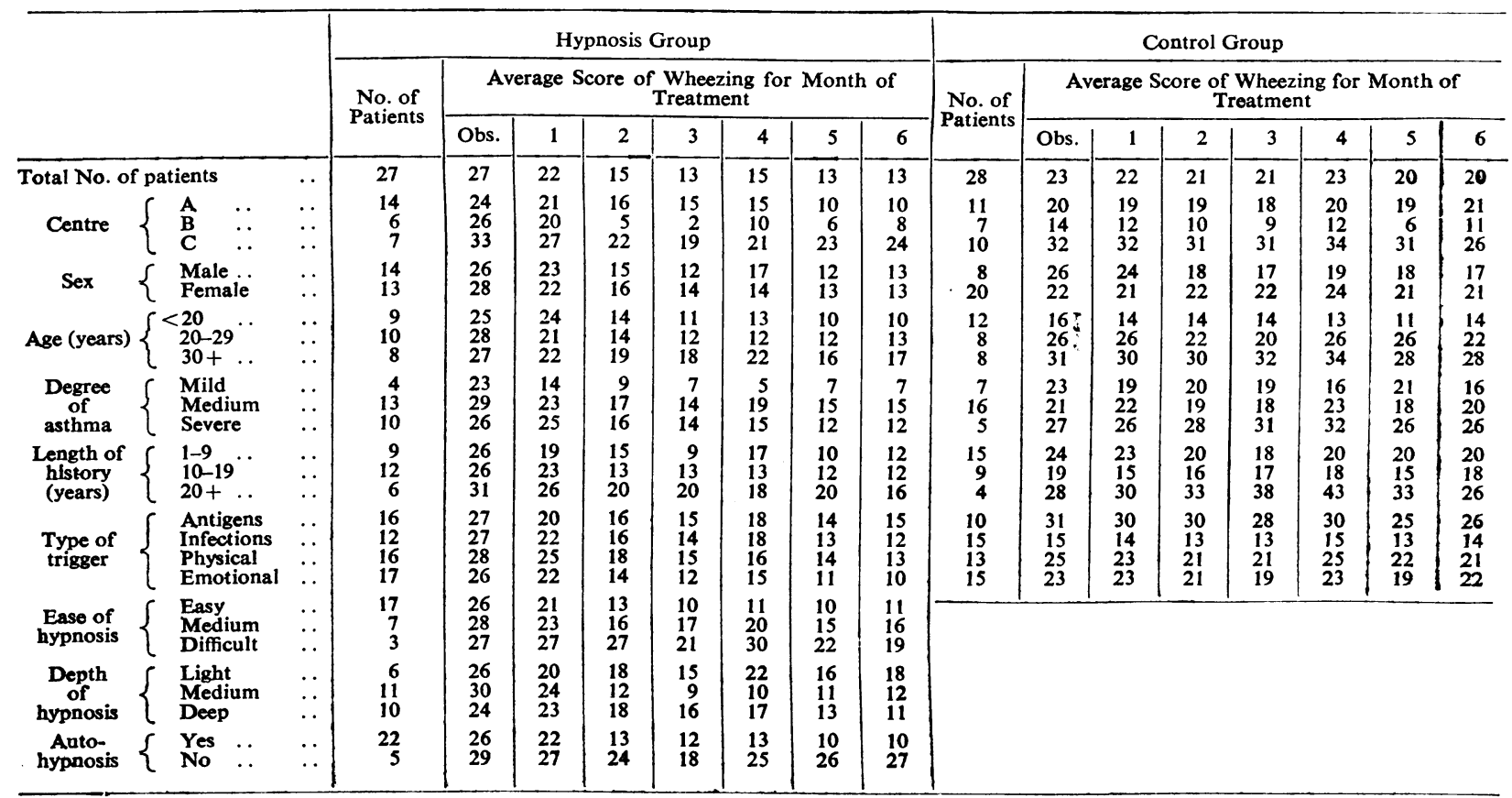


generally seen in work on asthma, some amongst the controls made good progress, others little, and some deteriorated; as a result the average of scores showed very little change over the six-months period.

The figures show an essential agreement with those of Morrison Smith and Burns (1960), who observed no significant benefit in a controlled trial of young asthmatics treated for four weeks by hypnosis: in our series, even with daily autohypnosis, only slight changes occurred in the first month of treatment.

In two cenires (A and B) 18 hypnosis patients continued to be treated with hypnosis and autohypnosis for a further six months. By the end of this period 12 of them were completely free from wheezing. This suggests that the optimum period of treatment is longer than the six months arbitrarily chosen for this trial.

The method of assessing results may be criticized in that it is based on subjective observations made by each individual patient. Certainly some patients think they are better, particularly after a new type of treatment, when objective evidence suggests that they are not (Edwards, 1960); but this is unlikely to be the sole explanation of the marked improvement in the wheezing in the hypnotized patients, particularly as the improvement was maintained over a period of months. The improvement too was often evident to the patient's relatives and the physician as well as to the patient himself. Although observer bias was minimized by the use of diaries, the actual recordings made in the diaries could have been influenced by "rapport" established between hypnotherapist and subject.

In addition to these subjective measurements, patients' sputum and blood were examined for eosinophils. No clear-cut physical changes emerge from this study, but it would appear that improvement is not likely to be readily demonstrable by objective tests carried out at infrequent intervals: no change was demonstrable in those few patients with marked eosinophilia or with eosinophils in their sputum. The number of patients with high counts was too small, so the question of clinical response related to eosinophilia or eosinophils in sputum must remain open.

In one centre (C) vital capacity, forced expiratory volume in one second, and peak flow were recorded at each interview, and, in those few cases only, very minor changes in both the control and hypnotherapy group were found during the six-months period, but in this centre least subjective improvement was recorded. From respiratory function studies very little objective information of value can be expected in groups of patients mostly under 40 years of age when those with emphysema have been omitted from the trial, because reasonably normal function is to be expected when the patient is not wheezing. It is common for the doctor in a clinic to see a patient, who may be a severe asthmatic, free from spasm: especially is this true of those who wheeze regularly and often severely at night yet clear completely in the daytime. Diary recordings of 24-hour spells free from wheeziness, substantiated by spouse or parents, are of great value in such instances. In more severe cases it is recognized that indices of airflow obstruction vary from day to day, and so their interpretation when performed at monthly intervals may be misleading in long-term studies. However, a sustained diminution in drugs taken and in frequency of severe attacks-if this be only symptomatic improvement-is of material value to asthmatic patients.
The difference between the centres is of great interest and warrants further research. Patients in centres $A$ and $B$ were treated by chest physicians who did their own hypnosis. In centre $C$ patients were seen by a chest physician who made the physical examinations and treated the controls but referred the hypnosis patients to a psychiatrist working in a psychiatric department.

Several other important points emerge from a study of Table VII. As might be expected, the greatest improvement in the hypnosis group was obtained in the patients under 30 and also in those with shorter histories; in them the asthma pattern is probably less deeply embedded and more rapidly removed or alleviated; nevertheless, improvement was also obtained in a number of older patients.

It is not surprising that the few mild cases of asthma in the series made the best progress, but the medium and severe cases also did well, the score of wheeziness in the latter being reduced to under half. There were only slight differences between the types of trigger and the response to treatment by hypnosis. This is of interest because it might have been thought that results in emotionally induced asthma would have stood out in bolder relief.

Analysis of a possible psychological basis of the patient's asthma was not attempted in this series, and only suggestions of relaxation and resultant improvement were given. Asthmatics are often understandably lacking in self-confidence; one aim was to increase this with the aid of hypnosis. Patients treated by hypnosis may sometimes become too dependent. In this series no patient in the hypnosis group had to be seen more often than the intervals laid down, so there was no evidence here of overdependence developing or increasing.

It has been said that simple symptom-removal of asthma may, if successful, be followed by the appearance of other stress symptoms, physical or mental. It was not possible in this short-term study to ascertain whether this phenomenon of "conversion" did in fact occur, although there is no positive evidence that it had. Hypnosis is shown in this paper to be of value in the symptomatic treatment of asthma. However, this finding is based purely on a subjective assessment (the reduction in wheezing and use of bronchodilators), and there remain many questions to be solved concerning satisfactory objective methods of assessment, the effect of hypnotic techniques used by different workers, and differing types of asthmatic patients.

\section{Summary}

Two groups of patients with asthma were treated at random either with hypnosis or with an antispasmodic which was new to the patient. Measurement of results was based entirely on an assessment made by the patients of the alteration in wheezing and in the use of bronchodilators, by a system of daily diary recordings.

Treatment by hypnosis was shown to be more effective symptomatically than treatment by an antispasmodic. The control group showed on an average little change throughout the period of the trial.

The trial was carried out in three centres; results in two centres where chest physicians gave hypnotic treatment were better than those in the third, where patients were referred to a psychiatric department. 
Male and female patients progressed equally well. Those under 30 years of age and those whose asthma had lasted 20 years or less fared the best. The severity of asthma and the type of trigger also provided differences in response to hypnosis; mild cases and those with emotional triggers did best, but good responses were observed in the other categories. Patients who were easily hypnotized, those who achieved deep trances, and, perhaps most important, those who could practise the daily use of autohypnosis did best.

Despite the many questions yet to be answered, hypnosis is of value in the symptomatic treatment of asthma as assessed by the reduction in wheezing and in the use of drugs.

We are indebted to Dr. R. S. Bruce Pearson for allowing patients under his care to be studied in this trial by two of us (Lionel Fry and A. A. Mason). We would like to acknowledge, with thanks, the most valued help given by two members of the Statistical Research Unit of the Medical Research Council: Dr. Ian Sutherland, who helped greatly in planning the trial, and Miss B. J. Kinsley, who converted the data on the charts into comprehensible tables and who gave most valuable help and advice in preparing the paper. Our thanks are due to Mrs. M. Curry (Colindale Hospital) and to Mr. J. Maher-Loughnan for painstakingly crosschecking the data.

\section{REFERENCES}

Ambrose, G. J., and Newbold, G. (1958). A Handbook of Medical Hypnosis, 2nd ed. Baillière, Tindall and Cox London.

Edwards, G. (1960). Brit. med. J., 2, 492.

Francis, R. S., and Spicer, C. C." (1960). Ibid., 1, 297

Fry. A. (1957). Brit. med. J., 1, 1323.

Magonct, A. P. (1955). Hypnosis in Asthma. Heinemann, London.

Meares, A (1960). A System of Medical Hypnosis. Saunders. Smith, J. M. (1958). Lancet, 2, 1248.

- and Burns, C. L. C. (1960). Brit. J. Dis. Chest, 54, 78

Stewart, H. (1957). Brit. med. J., 1, 1320.

Waller, R. E., and Lawther, P. J. (1957). Ibid., 2, 1473.

\section{INFECTIOUS HEPATITIS IN A VILLAGE COMMUNITY}

\section{KATHLEEN T. FLANAGAN, M.B., B.S. D.Obst.R.C.O.G. \\ General Practitioner, Bourne End, Bucks}

The epidemiology of infectious hepatitis is still not fully understood. In this country sporadic cases are more common than epidemics, and case-to-case infection has been regarded as uncommon and multiple cases within a household as relatively rare. Furthermore, because the responsible virus has only recently been isolated by Rightsel et al. (1961) the diagnosis must be made on clinical grounds. Thus a febrile illness characterized by a prodromal phase with anorexia and nausea and followed by jaundice with liver-function tests indicating evidence of hepato-cellular damage and some degree of biliary obstruction is usually diagnosed as infectious hepatitis. The majority of cases run a benign course with clinical recovery taking place in about four to six weeks. An occasional case may progress to acute hepatic necrosis. The present epidemic is reported because of the large numbers of cases occurring within a closed community with a high incidence in children, multiple cases within families, and one fatality occurring in a young married woman.

The first case was diagnosed in January, 1960, and occurred in a child aged 5 attending a village primary school. During the next seven months a large number of cases of jaundice occurred in the village, and details of 61 have been included in this report, the number occurring in each month being shown in Table $I$ and the age distribution in Table II.

From these Tables it may be seen that the maximum age incidence fell in the primary school age-group and

Table I.-Number of Cases Occurring in Each Month

\begin{tabular}{|c|c|c|c|c|c|c|c|c|c|c|}
\hline No. of cases & $\underset{1}{\operatorname{Jan}}$ & $\mathrm{Feb}_{\mathbf{3}}$ & $\underset{6}{\operatorname{Mar}}$ & Apr & $\underset{12}{\text { May }_{1}}$ & $\begin{array}{r}\text { June } \\
16\end{array}$ & $\underset{6}{\text { July }}$ & $\underset{6}{\mathrm{Aug}}$ & Sept & Oct \\
\hline
\end{tabular}

Table II.-Age Distribution of 61 Patients

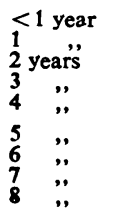

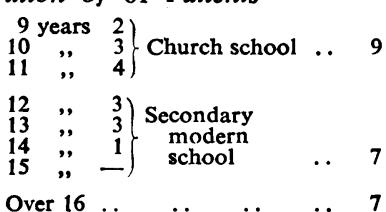

BY

\author{
JOHN LISTER, M.D., F.R.C.P. \\ Consultant Physician, Windsor Group of \\ Hospitals
}

that the incidence of new cases rose steadily to a maximum of 16 in June and thereafter fell steeply with no new cases after August.

\section{Clinical Features}

The 61 cases reported occurred within 35 families. In 20 families there was only one case, in seven there were two cases, in seven three cases, and in one family six cases. In most families the first case to occur was in a child attending the primary school. The incubation period for further cases appeared to be up to the expected 28 days, but as the epidemic developed there were often several separate sources of contact possible, making an exact determination of the incubation period impossible.

The clinical features followed the classical description of the disease. Prodromal symptoms appeared two to five days before jaundice developed, but extended over 10 days in one case. Nausea, anorexia, lassitude, and abdominal pain, with fever varying from 99 to $101^{\circ} \mathrm{F}$. $\left(37.2\right.$ to $\left.38.3^{\circ} \mathrm{C}.\right)$, were constant features. Vomiting was severe and persisted for two to three days in $20 \%$ of the cases, and in these epigastric pain was usually severe. Diarrhoea was present in a few cases. Jaundice with dark urine and pale stools was apparent by the fourth day in most cases. The liver was enlarged and tender for one to two weeks in mild cases but for longer periods in the more severe attacks. In six cases the jaundice persisted for four to five weeks, but in the remaining juvenile cases recovery was rapid and complete and no recurrence was reported. Epistaxis occurred in six cases and melaena was reported in the case of a child who had severe abdominal pain and diarrhoea during the second week of the illness. Pruritus was a troublesome symptom in several cases and lasted for two weeks after the disappearance of jaundice in one case. The adult patients were all more seriously ill, and a married woman of $\mathbf{3 1}$ developed acute hepatic necrosis and died in hepatic coma.

Where possible the children were isolated from other members of the family and all were excluded from 